\title{
The arsenic green
}

\section{William Morris seemed indifferent to the fact that his wallpapers contained arsenical pigments.}

\section{Andy Meharg}

William Morris (1834-1896) was a utopian idealist whose life was full of contradictions. He was a progenitor of the green movement and decried the environmental and human degradation caused by industrial activity. But he was also a successful capitalist who supplied the bourgeoisie with expensive interior décor. This paradox is most disturbingly evident in his intimate associations with arsenic.

His father, William Morris senior, helped set up the mining company Devon Great Consols (DGC), in its day the largest producer of arsenic in the world. William Morris used his income from shares in DGC to finance his design company Morris, Marshall, Faulkner \& Co. (later Morris \& Co). He also served as a director of DCG between 1871 and 1875 , when arsenic production was at its height. But he was increasingly influenced by the growing socialist movement and resigned his directorship in 1875 .

The environmental pollution caused by DGC was vast and persists to this day. Working conditions were atrocious. Workers suffered widely from skin lesions known as arsenic 'pock', which caused great discomfort, and many died from arsenicrelated lung disease.

From 1867 onwards, DGC was the major supplier of arsenic for the production of green pigments following the synthesis in the late eighteenth century of copper arsenite, named Scheele's green after its discoverer. These pigments were widely used in wallpapers. In damp rooms, fungi living on the wallpaper paste turned the arsenic salts into highly toxic trimethylarsine. Arsenic pigments, which were also used extensively in paints and to dye clothes, paper, cardboard, food, soap, and artificial and dried flowers, were responsible for untold numbers of cases of chronic illness and many deaths.

Was Morris using the arsenic from DGC in his own products? Evidence to suggest that he was comes from correspondence with Thomas Wardle, his dye manufacturer. In one letter, dated 3 October 1885 , responding to an enquiry from a concerned customer (Mr Nicholson), Morris dismissed the concerns of the medical professions and popular press about arsenic poisoning wallpapers coloured with arsenic pigments. "As to the arsenic scare, a greater folly is hardly possible to imagine: the doctors were being bitten by witch fever."

A second letter three days later stated: "Of course it is proving too much to prove that the Nicholsons were poisoned by wall-papers; for if they were a great number of people would be in the same plight and we should be sure to hear of it." This blasé response to the harmful effect that his wallpapers might have been having on his customers' health is remarkable, given the documented occurrence of arsenic poisoning at DGC.

To help me investigate the possible use of arsenic pigments in William Morris wallpapers, the William Morris Gallery in London kindly sent me a small piece of an early example of the 'Trellis' pattern wallpaper. The Trellis pattern is believed to be Morris's first wallpaper and was produced from 1864 onwards. I analysed the green pigment by energy-dispersive analysis and showed unequivocally that the coloration was caused by a copper arsenic salt. The beauty that William Morris wallpapers brought to a room must have had a health cost, at least in damp houses.

It is easy to be harsh on William Morris for his double standards with respect to industry and pollution. In his defence, he was a product of his age, when environmentalism was in its infancy. $\mathrm{He}$ was actually a positive force in this movement. His political creed developed over several decades, and by the end of his life, when he was most revolutionary, his links with industry were in the past.
Hidden danger:

in damp houses, the green pigment in William Morris's wallpaper could have released toxic arsenic compounds.

However, as a writer who demonized the industrial practices of his time as dehumanizing, he is almost as silent as a stone on his own role in the most polluting of industries, arsenic production. The Wardle letters - all that survive of his thoughts on his connections with arsenic - show only indifference, not regret.

Andy Meharg is in the School of Biological Science, Cruikshank Building, Aberdeen University,

Aberdeen AB24 3UU, UK. helped to rationalize interesting results, and whose later work using much faster computers predicted utterly non-classical organometallics, some of which were later verified experimentally.

Some interviewees offer insights that are worthy of further discussion. Jacqueline K. Barton is self-reflective and generous to students and colleagues in tracing her career path. Starting on tenure track at Hunter College in New York, she moved to Columbia University, where she was promoted to full professor, and then moved to the Cali- fornia Institute of Technology, where she holds an endowed professorship. She notes in passing that "the paths of woman professors tend to be non-traditional". Barton concludes the interview: "You can be a woman scientist in a major research institution and also be a person with a family and be happy." It is not a self-satisfied remark but rather active encouragement to young women pondering futures in science.

This book makes interesting light reading, especially for chemists who have watched the field develop over the past 30 to 60 years.
One might wish for a preface that provides some integration and perspective, for example in considering the career paths of the three women interviewed (Barton, Mildred Cohn and Reiko Kuroda). Nonetheless, the book makes a worthwhile contribution to the oral history of science, and I recommend it for both libraries and individuals.

Arthur Greenberg is professor of chemistry and dean of the College of Engineering and Physical Sciences, University of New Hampshire, Durham, New Hampshire 03824, USA. He is the author of The Art Of Chemistry. 